\section{LOOKING GOOD}

Alexandra Workwear PIc

Alexandra House

Britannia Road

Patchway

Bristol

Avon BS12 5TP

Tel: 01179594444

MPL: bealtbcare uniforms

\section{BIRKETT \& PHIILIPS}

1 Mill Buildings

Lea Bridge

Matlock

Derbyshire DE4 5AG

Tel: 01629534331

Fax: 01629534691

MPL: mail order.natural

fabrics

Contact: Patricia Gregory

Date established: 1920

\section{Denroy International Ltd}

Unit 16

Princeton Mews

167-169 London Road

Kingston-upon-Thames

Surrey KT2 6PT

Tel: 01819746674

MPL: hairbrusbes (denmaw)
Buyona Health \& Bodycare

Co

PO Box 13

Unit 5

Lealand Way

Boston

Lincolnshire

PE21 7SW

Tel: 01205362742

MPL: bealth bosiery

See display advertisement below.

\section{Castle Lodge}

2 Somerset Road

Handsworth Wood

Birmingham

West Midlands

B20 2JD

Tel: 01215548129

Contact: Mrs Gillian Law

\section{Chilprufe Mail Order}

PO Box 309

Leicester

Leicestershire

LE5 $5 \mathrm{NW}$

Tel: 01162733622

MPL: mail order clotbing
Disfigurement Guidance

Centre/Laserfair

PO Box 7

Cupar

Fife

KY15 4PF

Tel: 01334870281

\section{National Osteoporosis}

Society

PO Box 10

Radstock

Bath

Avon

BA3 3YB

Tel: 01761432472

MPL: information, advice on osteoporosis

\section{Scholl Consumer Products}

Ltd

Customer Services Dept

475 Capability Green

Luton

Bedfordshire

LU1 3LU

Tel: 01582482929

MPL: footwear
Society of Shoe Fitters

The Anchoridge

28 Admirals Walk

Hingham

Norwich

Norfolk

NR9 4JL

Tel: 01953851171

MPL: shoe fitters

\section{Specialist Optical Source} Ltd

57 Dukes Wood Drive

Gerrards Cross

Buckinghamshire

SL9 7LJ

Tel: 01753888411

MPL: magnifiers

Taylor Clark Fashions PO Box 27

Worsley

Manchester

Greater Manchester

M28 2SE

Tel: 01617901807

MPL: specialist clotbing, footwear

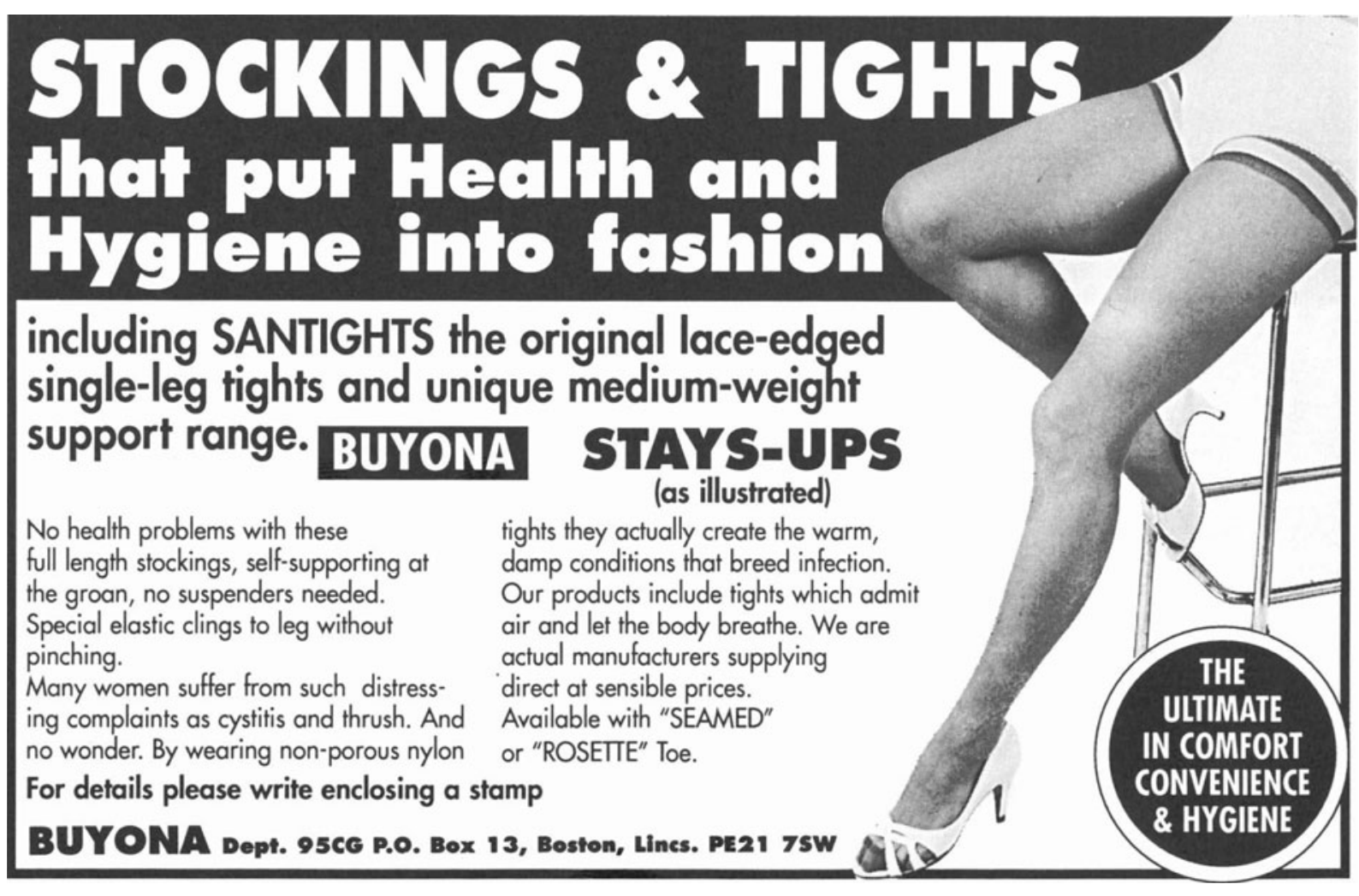

